\title{
Clinical Effects of Electromagnetic Stimulation as an Adjunct to Periodontal Therapy*
}

\author{
B. Steffensen,† R. G. Caffesse,† C. T. Hanks, $\ddagger$ J. K. Avery $\ddagger$ and \\ N. Wright†
}

Accepted for publication 1 June 1987

\begin{abstract}
THE CLINICAL EFFECTS OF ELECTROMAGNETIC STIMULATION (EMS) on periodontal soft tissues and alveolar bone level were studied among 23 patients. The sides of the arch to receive EMS were randomly selected and exposed for a period of eight weeks following periodontal surgery. The contralateral control sides received surgery only. The electromagnetic signal was a multiple pulse signal with 21 asymmetrical quasirectangular pulses per burst and a burst frequency of $16.9 \mathrm{~Hz}$. The peak magnetic field strength reached 0.46 Gauss. Changes from baseline in clinical attachment level, probing depth, and radiographic alveolar bone level were assessed at six, 12 , and 18 months postsurgically.

A greater gain of clinical attachment level following EMS was observed only for pockets with initial depth of 1 to $3 \mathrm{~mm}$. There were no consistent differences between test (EMS) and control sides in the change of clinical attachment level or probing depth for pockets deeper than $4 \mathrm{~mm}$. Radiographically, the test sides demonstrated statistically significant gain of alveolar bone level compared with the control sides at six months following surgery. Hereafter, the rates of change were similar in the stimulated and unstimulated sides, and the total gain of alveolar bone level remained greater in the test side throughout the observation period.

Within the limitations of this study, it was concluded that electromagnetic stimulation does not promote gains in clinical attachment or alveolar bone level to the extent that it can be recommended as an adjunct to conventional periodontal therapy.
\end{abstract}

The interest in electrical stimulation for repair and regeneration was initiated by the discovery that piezoelectrical currents were produced in long bones when placed under tension. ${ }^{1,2}$ Such currents have also been observed in bone of the mandible in $\operatorname{dogs}^{3}$ as well as in humans. ${ }^{4}$ Later it was demonstrated in rabbits that electrical stimulation by electrodes ${ }^{2}$ or charged Teflon films ${ }^{5}$ induced formation of bone around the charged element. Likewise, bone formation was found to be enhanced around cathodes placed in experimental fractures or wounds of beagle dog femora as a result of an increase in the rate of osteoblast mitosis. ${ }^{6}$ Several investigators have subsequently studied the effects of electrical currents on osteogenesis in animals using different electrical modalities such as direct current, ${ }^{7}$ pulsed voltage sources, ${ }^{8}$ constant-current sources, ${ }^{9}$ and alternating currents. ${ }^{10}$ Application of electrical stimuNY.

* Supported by Kerr Division of Sybron Corporation, Rochester,

$\dagger$ Department of Periodontics, University of Michigan, School of Dentistry, Ann Arbor MI 49109.

$\ddagger$ Dental Research Institute, University of Michigan. lation by electrodes to amputated limbs of frogs ${ }^{11}$ and rats $^{12}$ resulted in partial regeneration, a process that does not normally take place.

Clinical studies in humans have reported enhanced healing and bone reorganization of nonunion fractures and pseudoarthroses by electrical stimulation following long-term unsuccessful conventional treatments. ${ }^{13-17}$ Although a major part of these results are derived from uncontrolled studies or case reports, there seems to be evidence of a positive effect of the electrical impulses. $^{18,19}$

Several investigators have reported that alveolar bone responds to electrical stimuli in a manner similar to long bone, ${ }^{3,4,20}$ and electrical stimulation has been proposed to facilitate tooth movements ${ }^{21,22}$ and to support healing following surgical procedures for cleft palate repair. ${ }^{21}$ In studies of electrical stimulation in periodontal therapy, ${ }^{23-25}$ electrodes or galvanic elements were placed into interproximal or furcation defects caused by naturally occurring periodontitis in beagle dogs. Although this treatment resulted in enhanced endosteal bone apposition around the electrodes, no clinically or 
radiographically significant changes in the depth of the defects were observed.

The main risks of placing electrodes into the defects are electrolysis and infection. Noninvasive bioelectrical therapies, i.e., electromagnetic or electrostatic fields, have been introduced to eliminate these side effects. Results from controlled studies in rats ${ }^{26}$ and beagle dogs ${ }^{13,27}$ and from clinical treatment of pseudoarthroses and nonunion fractures in humans ${ }^{15}$ have indicated that such noninvasive electrical fields can stimulate bone regeneration as well.

During previous studies in our laboratories, a noninvasive electromagnetic signal was developed and tested. When exposed to stimulation with this electromagnetic field, subcultures of periosteal cells from fetal rat calvaria increased their rate of DNA and protein synthesis. ${ }^{28-30}$ In addition, stimulation with this signal enhanced the formation of bone in experimental wounds in rats ${ }^{31}$ and beagle dogs. ${ }^{32,33}$ Based upon these preliminary findings, it was the aim of the present study to test the clinical effects of electromagnetic stimulation (EMS) on human periodontal soft tissue and alveolar bone during a postsurgical healing period.

\section{MATERIALS AND METHODS}

Twenty-four patients (13 female, 11 male) with a mean age of 49 years (range 24-67 years) were selected for the study at the School of Dentistry, University of Michigan. Having received oral hygiene instruction, scaling, and root planing, these patients were still in need of periodontal surgery in two contralateral quadrants of the mandible or maxilla. Criteria for selection were pocket probing depths of 5 to $6 \mathrm{~mm}$ and associated radiographic bony defects on two pairs of contralateral teeth (molars or premolars). The patients were appraised of the study, and written consents were obtained consistent with the policies of the University of Michigan and the National Institutes of Health.

One side was randomly assigned as test side, while the contralateral side served as control side. Modified Widman flap surgery ${ }^{34}$ without bone correction was performed on both sides at the same appointment. Following the surgery, all patients received biweekly polishing for two months and were then seen every three months for prophylaxis. The test sides were, in addition, exposed to an electromagnetic field during a period of two months starting on the day of the surgery. This electromagnetic field was created between a pair of coils $(28 \mathrm{~mm} \times 12 \mathrm{~mm}, 150$ turns of No. 40 trifilar wire) that were placed parallel, buccally and lingually, along the two test teeth on a bite plane splint (Fig. 1). The patients were instructed to wear this modified splint for at least eight hours per day, to clean it meticulously, and to report any malfunction immediately. The signal that generated the electromagnetic field came from a pocket-sized, battery driven $(9 \mathrm{~V})$

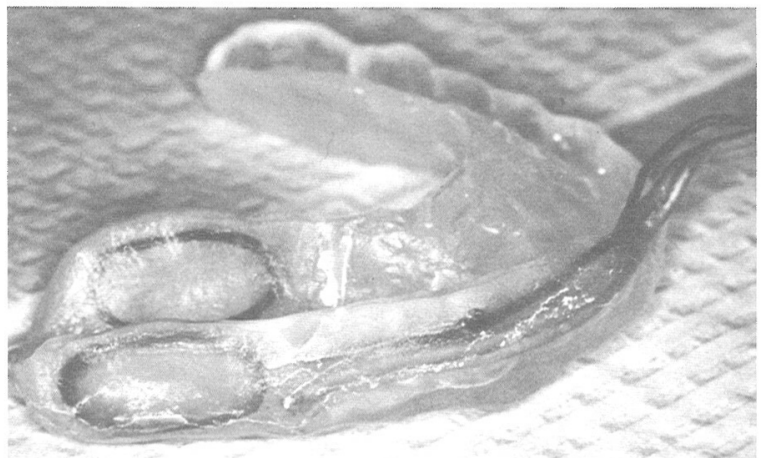

Figure 1. The modified bite plane splint, on which the coils were mounted. The cord connects these coils with the extraoral signal generator.

extraoral device and was transmitted to the coils through a cord connection. This signal was a multiple pulse signal with 21 quasirectangular pulses per burst, and with a burst frequency of $16.9 \mathrm{~Hz}$. The amplitude across the field coils was $5900 \mathrm{mV}(\mathrm{P}-\mathrm{P})$ and $83 \mathrm{mV}$ (P-P) when measured between the field coils with a search coil (Fig. 2). The peak magnetic force was approximately 0.46 Gauss. The signal characteristics were tested and calibrated biweekly during the two-month stimulation period.

At six, 12, and 18 months postsurgery, the probing depth and clinical attachment level from the cementoenamel junction were measured at six well-defined sites for each test and control tooth. One examiner performed all clinical measurements while other investigators performed the clinical treatment procedures in a blind study design. The changes of these parameters from baseline per side, as well as the differences in changes between experimental and control sides, were determined for each reevaluation interval. The statistical analyses of these data were based upon total mean values per side and also on three presurgical probing depth categories (1-3 mm, 4-5 $\mathrm{mm}$, larger than $6 \mathrm{~mm}$ ) using the paired $t$ test.

Radiographs of the two test teeth (EMS) and of the two contralateral control teeth were obtained prior to surgery and at six, 12, and 18 months. These radiographs were exposed with a system developed to produce identical images ${ }^{35}$ using individual bite blocks and a cone-guiding device. This system has previously been shown to produce angulation errors within three degrees, resulting in a standard deviation of $0.1 \mathrm{~mm}$ when measuring alveolar crest levels. ${ }^{35}$ All exposures were made at $70 \mathrm{kVP}$ and $15 \mathrm{~mA}$ with similar exposure times, and the films* were developed, fixed, and rinsed under identical conditions. All radiographs were evaluated by one examiner at a magnification seven times normal on a modified Schei ruler. ${ }^{36}$ The height of the alveolar periodontal bone was expressed in percentage of the root length at $5 \%$ increments. The cementoena-

\footnotetext{
* Ektaspeed EP21, Eastman Kodak Co, Rochester, NY.
} 


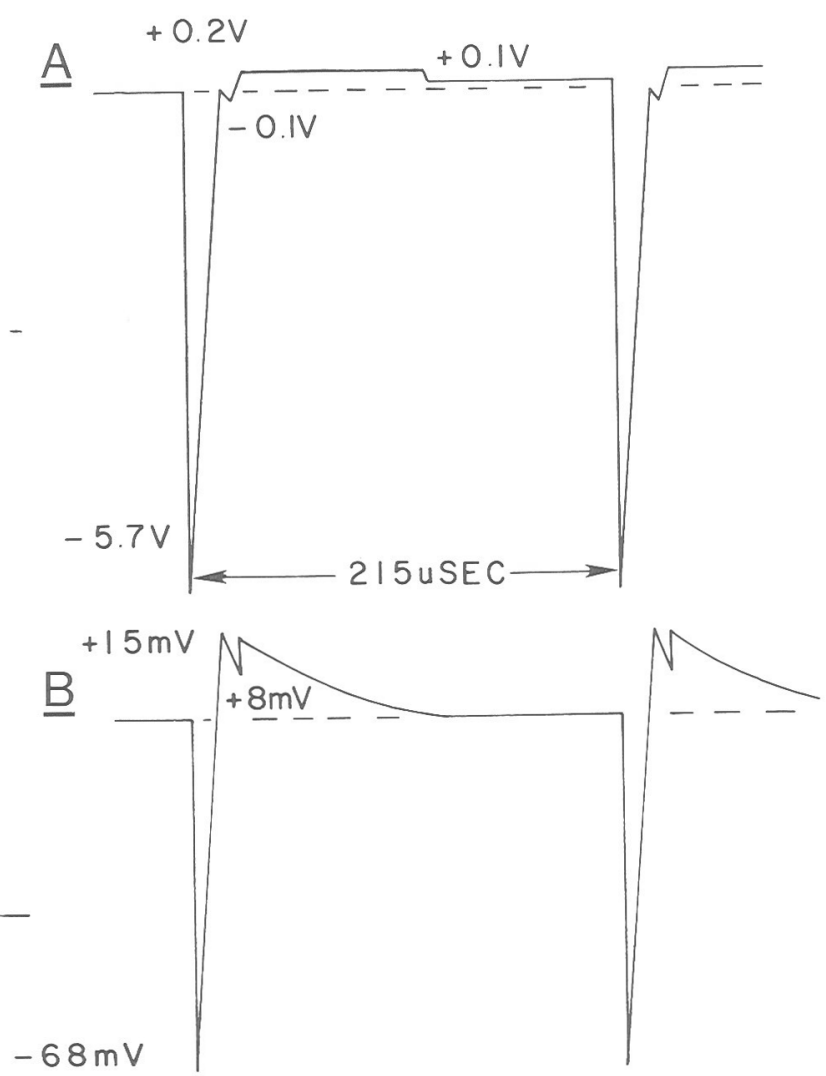

Figure 2. Drawing illustrating the characteristics of the signal, which generates the electromagnetic field as measured across the field coils (A) and between the field coils with a search coil (B).

mel junction (CEJ) or the margin of any covering restoration served as the coronal, and the root tip as the apical reference point, respectively. In angular defects, the most apical point was defined by the presence of a normal lamina dura and normal width of the periodontal membrane space. For analysis, the alveolar bone level was determined for each side as the average of the changes at four interproximal measurement sites. The radiographic changes from baseline were calculated for each reevaluation interval, and the differences between test and control sides were compared. These proportional data were analyzed by the nonparametric Wilcoxon rank sum test.

In the analysis of both soft tissue and alveolar bone level data, the patient served as the statistical unit and a significance level of $P<0.05$ was applied. Only baseline values with corresponding reevaluation data were used for the analyses.

\section{RESULTS}

At the time of the data evaluation, twenty-three patients had been maintained in the study for six months, 18 for 12 months, and ten patients for 18 months following the electromagnetic stimulation period. The decrease in number of patients with time does not indicate "drop-outs," but reflects the varying length of time that the patients have been in the study.

\section{Probing Depth and Clinical Attachment Level}

Both test and control sides showed statistically significant probing depth reduction from baseline at all reevaluation intervals within each initial probing depth category (Table 1, Fig. 3). Although not statistically significantly different, the probing depth reduction of shallow pockets $(1-3 \mathrm{~mm})$ was larger on the test side, while the reduction of the pockets over $4 \mathrm{~mm}$ was greater on the control side. Likewise, the differences in total mean changes between test and control sides were not statistically significantly different.

There was a consistent gain of clinical attachment level from baseline in both test and control sites with an initial probing depth of $4 \mathrm{~mm}$ or deeper (Table 2 , Fig. 4). This gain was, however, only statistically significant for pockets over $6 \mathrm{~mm}$. Control sites of initially 1 to $3 \mathrm{~mm}$ showed a statistically significant loss of attachment at 6,12 , and 18 months while the changes in the experimental sites were insignificant for this probing depth category.

Evaluation of the changes in clinical attachment level, when based upon total mean values per side, demonstrated statistically significantly more gain in the test sides than the control sides at six and 12 months (Table 2, Fig. 4). However, additional analyses, when based upon the presurgical probing depth categories (1$3,4-5$, or over $6 \mathrm{~mm}$ ), revealed that such a difference was limited to the sites with initial depths of 1 to $3 \mathrm{~mm}$. This difference among the shallow pockets, although only statistically significant at 6 months, remained consistent throughout the 18-month observation period (Table 2, Fig. 4).

\section{Alveolar Bone Level}

The test sides demonstrated at six, 12 , and 18 months an average gain of alveolar bone level (Table 3, Fig. 5), the size of which increased from 6 to 18 months of the reevaluation period. The control sides, in contrast, showed a loss of alveolar bone height at six and 12 months postsurgery. However, the magnitude of this loss decreased from six to 12 months and at 18 months a gain in alveolar bone level was demonstrated.

Although the gain of alveolar bone at all reevaluation intervals was larger on the test side than on the control side, the difference was only statistically significant at six months after the surgery (Table 3, Fig. 5).

\section{DISCUSSION}

In the present study an electromagnetic signal that had been developed and tested previously in our laboratories was applied and evaluated clinically as an adjunct to surgery in the periodontium.

In the test sides that received EMS, a consistently larger gain of clinical attachment was observed for only sites with an initial probing depth of 1 to $3 \mathrm{~mm}$. However, it has previously been shown that surgical 
Table 1

Mean Reduction of Pocket Probing Depth from Baseline at the Various Examination Intervals Described for Three Initial Probing Depth Categories and for Total Means per Side*

\begin{tabular}{|c|c|c|c|c|c|c|c|c|c|c|c|c|c|}
\hline \multirow{2}{*}{$\begin{array}{l}\text { Initial probing } \\
\text { depth }\end{array}$} & & \multicolumn{4}{|c|}{ 6-Month examination } & \multicolumn{4}{|c|}{ 12-Month examination } & \multicolumn{4}{|c|}{ 18-Month examination } \\
\hline & & $N$ & $\mathrm{Ch}$ & MD & $\mathrm{D}$ & $N$ & $\mathrm{Ch}$ & GD & SD & $N$ & $\mathrm{Ch}$ & MD & SD \\
\hline & Con & 22 & 0.1 & 15 & 0.63 & 16 & & 0.30 & 0.63 & 9 & & 0.16 & 0.43 \\
\hline $4-5$ & $\begin{array}{l}\text { Test } \\
\text { Control }\end{array}$ & 23 & & 8 & 0.82 & 17 & & 0.02 & 0.79 & 10 & & -0.15 & 0.79 \\
\hline & $\begin{array}{l}\text { Test } \\
\text { Control }\end{array}$ & 12 & $\begin{array}{l}2.11 \dagger \\
2.66 \dagger\end{array}$ & -0.55 & 1.27 & 9 & $\begin{array}{l}1.71 \dagger \\
2.35 \dagger\end{array}$ & -0.63 & 1.41 & 7 & $\begin{array}{l}2.16 \dagger \\
2.63 \dagger\end{array}$ & -0.47 & 1.11 \\
\hline $\begin{array}{r}\text { Total } n \\
\text { per } \mathrm{s}\end{array}$ & $\begin{array}{l}\text { Test } \\
\text { Control }\end{array}$ & 23 & $\begin{array}{l}0.89 \dagger \\
0.83 \dagger\end{array}$ & 0.09 & 0.70 & 18 & $\begin{array}{l}1.08 \dagger \\
0.97 \dagger\end{array}$ & 0.11 & 0.70 & 10 & $\begin{array}{l}1.21 \dagger \\
1.28 \dagger\end{array}$ & -0.07 & 0.81 \\
\hline
\end{tabular}

* MD = mean difference; $N=$ number of subjects.

$\dagger$ Statistically significantly different from baseline $(P<0.05)$.

$\S$ Statistically significant difference $(P<0.05)$.

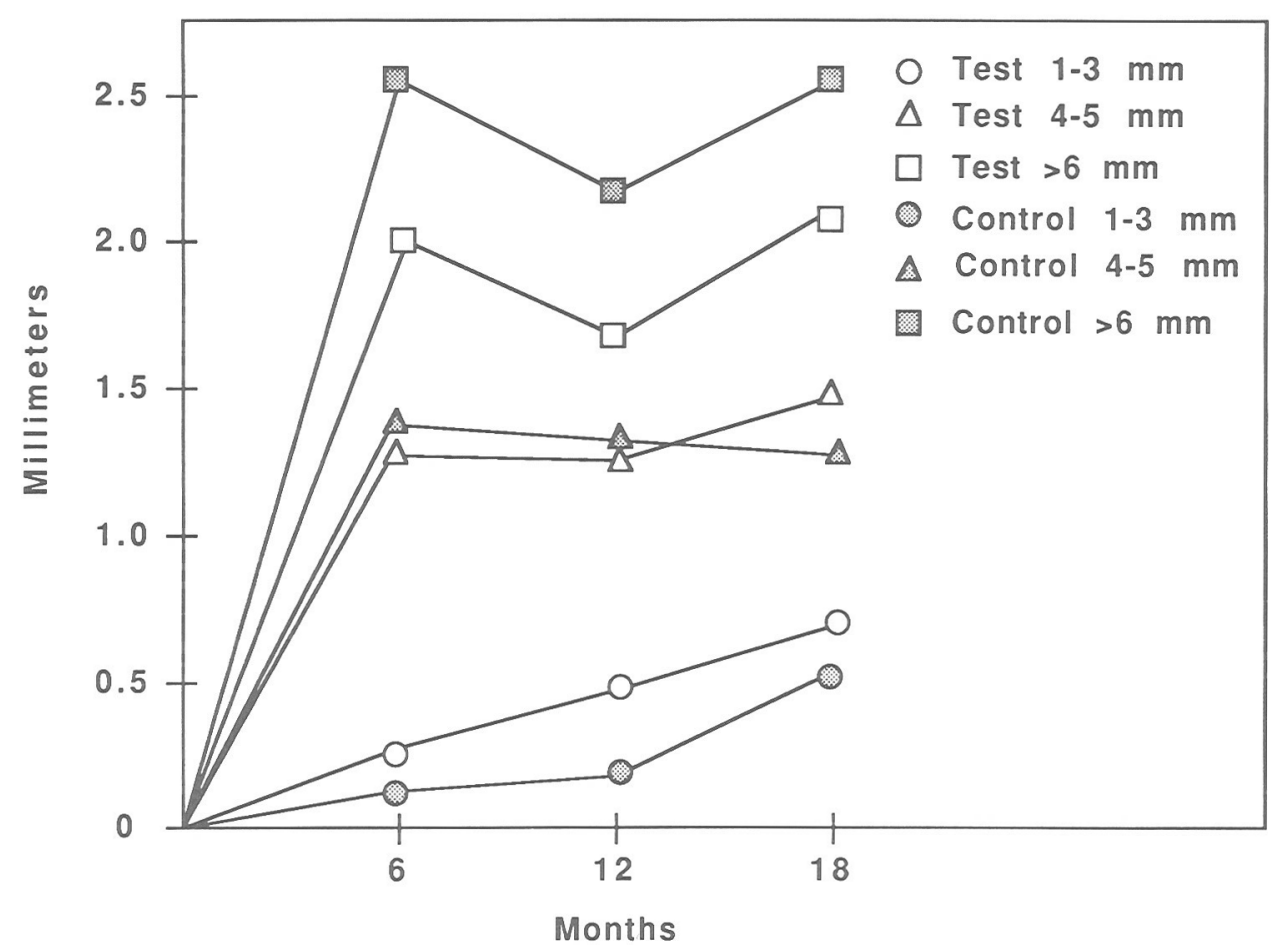

Figure 3. Reduction in pocket probing depth from baseline at six, 12, and 18 months reevaluation for each initial probing depth category.

procedures in pockets of this depth are not indicated since they do not promote better treatment results than nonsurgical therapy. ${ }^{37}$ In the present study, these shallow sites were only approached surgically to gain access to areas of more severe disease involvement. Among the initially deeper pockets, no consistent differences between electromagnetically stimulated and control sites were detected. The control side changes in clinical attachment level and probing depth were observed to be comparable with results from previous studies of periodontal surgical procedures. ${ }^{37-40}$

These limited clinical effects of EMS on the periodontal soft tissues appeared to be in contrast to results of studies performed prior to this clinical application. Thus, increased DNA and protein synthesis had been demonstrated among fetal rat calvarium cell application of an identical electromagnetic signal. ${ }^{28-30}$ Other investigators ${ }^{18,41}$ had shown similar findings in fibroblast cultures following exposure to electrical stimulation. In addition, well-developed collagen fibers and a significantly greater gain of connective tissue attachment had been demonstrated histologically in naturally occurring periodontal disease sites in beagle dogs that received EMS for 14 or 28 days compared with unstimulated control sites (unpublished). Also these results were in agreement with previous studies that had shown that electrical stimulation in beagle dog femora promoted an increased rate of mitosis among mesenchymal and bone cells around experimental fractures. ${ }^{6}$

Radiographically, at all reevaluation intervals there 
Table 2

Mean Changes of Probing Attachment Level from Baseline at the Various Examination Intervals

Described for Three Initial Probing Depth Categories and for Total Means per Side*

\begin{tabular}{|c|c|c|c|c|c|c|c|c|c|c|c|c|c|}
\hline \multirow{2}{*}{$\begin{array}{l}\text { Initial probing } \\
\text { depth }\end{array}$} & & \multicolumn{4}{|c|}{ 6-Month examination } & \multicolumn{4}{|c|}{ 12-Month examination } & \multicolumn{4}{|c|}{$\begin{array}{l}\text { 18-Month } \\
\text { examination }\end{array}$} \\
\hline & & $N$ & Change & MD & $\mathrm{SD}$ & $N$ & Change & $\mathrm{MD}$ & SD & $N$ & Change & MD & SD \\
\hline $1-3 \mathrm{~mm}$ & $\begin{array}{l}\text { Test } \\
\text { Control }\end{array}$ & 22 & $\begin{array}{l}-0.14 \\
-0.58 \S\end{array}$ & $0.44 \dagger$ & 0.81 & 16 & $\begin{array}{l}-0.007 \\
-0.40 \S\end{array}$ & 0.39 & 0.99 & 9 & $\begin{array}{c}0.17 \\
-0.45 \S\end{array}$ & 0.62 & 1.08 \\
\hline $4-5 \mathrm{~mm}$ & $\begin{array}{l}\text { Test } \\
\text { Control }\end{array}$ & 23 & $\begin{array}{l}0.39 \\
0.10\end{array}$ & 0.29 & 0.94 & 17 & $\begin{array}{l}0.37 \\
0.24\end{array}$ & 0.14 & 0.99 & 10 & $\begin{array}{l}0.51 \\
0.44\end{array}$ & 0.07 & 0.77 \\
\hline$\geq 6 \mathrm{~mm}$ & $\begin{array}{l}\text { Test } \\
\text { Control }\end{array}$ & 12 & $\begin{array}{l}1.72 \S \\
1.63 \S\end{array}$ & 0.09 & 1.41 & 9 & $\begin{array}{l}1.09 \S \\
1.36\end{array}$ & -0.28 & 1.90 & 7 & $\begin{array}{l}1.87 \S \\
1.63\end{array}$ & 0.23 & 1.59 \\
\hline $\begin{array}{l}\text { Total means } \\
\text { per side }\end{array}$ & $\begin{array}{l}\text { Test } \\
\text { Control }\end{array}$ & 23 & $\begin{array}{r}0.17 \\
-0.13\end{array}$ & $0.30 \dagger$ & 0.50 & 18 & $\begin{array}{l}0.38 \S \\
0.09\end{array}$ & $0.33 \dagger$ & 0.42 & 10 & $\begin{array}{l}0.63 \S \\
0.36\end{array}$ & 0.27 & 0.50 \\
\hline
\end{tabular}

* MD $=$ mean difference; $N=$ number of subjects.

$\dagger$ Statistically significant difference $(P<0.05)$.

$\S$ Statistically significantly different from baseline value $(P<0.05)$.

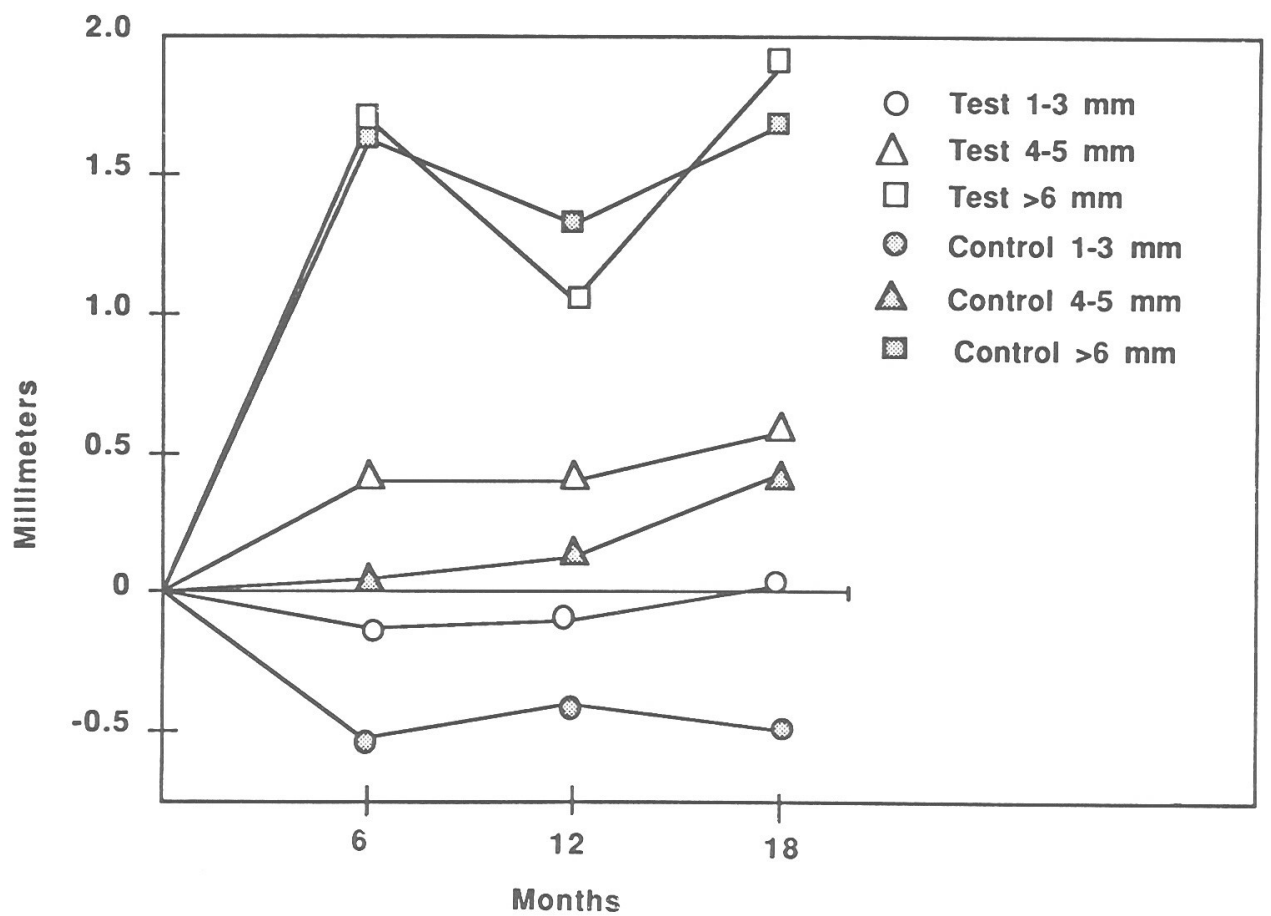

Figure 4. Changes in clinical attachment level from baseline at six, 12, and 18 months reevaluation for each initial probing depth category.

Table 3

Mean Changes of Alveolar Bone Level in Per Cent of Root Length from Baseline at the Various

Examination Intervals Described for Total Means per Side*

\begin{tabular}{|c|c|c|c|c|c|c|c|c|c|c|c|c|c|}
\hline & & \multicolumn{4}{|c|}{ 6-Month examination } & \multicolumn{4}{|c|}{ 12-Month examination } & \multicolumn{4}{|c|}{ 18-Month examination } \\
\hline & & $N$ & Change & MD & SD & $N$ & Change & MD & $\mathrm{SD}$ & $N$ & Change & $\mathrm{MD}$ & SD \\
\hline $\begin{array}{l}\text { Total means } \\
\text { per side }\end{array}$ & $\begin{array}{l}\text { Test } \\
\text { Control }\end{array}$ & 23 & $\begin{array}{r}1.62 \\
-1.13\end{array}$ & $2.75 \dagger$ & 3.35 & 16 & $\begin{array}{r}2.39 \\
-0.55\end{array}$ & 2.94 & 3.21 & 10 & $\begin{array}{l}3.42 \\
0.93\end{array}$ & 2.49 & 2.83 \\
\hline
\end{tabular}

${ }^{*} \mathrm{MD}=$ mean difference; $N=$ number of subjects.

$\dagger$ Statistically significant difference $(P<0.05)$.

was consistently a larger gain of alveolar bone level on the sides that received EMS than on the control sides. Since the control side treatment, the modified Widman flap surgical design with no bone correction, previously has been shown to promote the most favorable post- surgical healing in bony defects, ${ }^{42}$ it is noteworthy that the gain of alveolar bone level in the test sides consistently was larger than that of the control sides. The continuing long-term gains in alveolar bone level in both test and control sides during the whole observation 


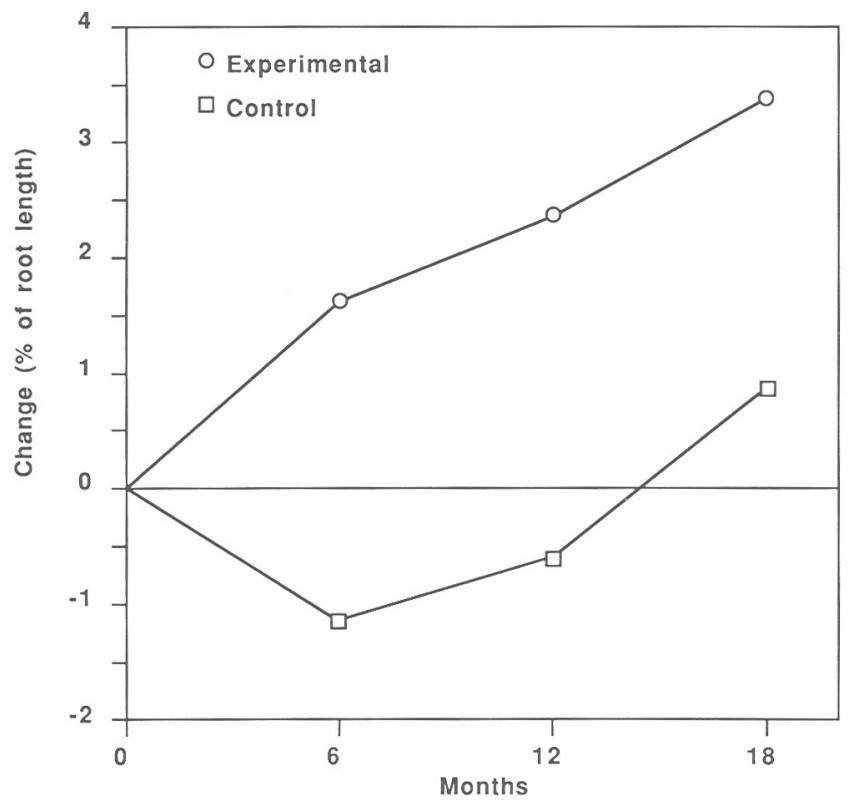

Figure 5. Mean changes in radiographic alveolar bone level from baseline at six, 12, and 18 months reevaluation expressed in per cent of root length.

period apparently reflect the slow processes of bone regeneration.

Another determinant to consider is the oral hygiene status that also has been shown to affect the amount of regeneration in bony defects. ${ }^{43}$ In the present study, the patients received prophylaxis biweekly during the initial two months and thereafter once every three months. This schedule of prophylaxis visits may explain, in part, why the gain of alveolar bone level in the control sides was less than that observed in other studies. ${ }^{42,43}$ Thus in these studies, patients who were placed on a biweekly prophylaxis schedule demonstrated almost complete bone fill of intrabony defects following periodontal surgery. ${ }^{43}$

The numerical expressions of the gains in alveolar bone level may have been affected by inclusion of defects of varying morphology into this study, although it was attempted to select angular type defects primarily. Since the changes of bone level were expressed as the averages per side of the alterations at several interproximal measurement sites along the study teeth, the magnitudes of the changes were, as expected, lower than those seen in studies of angular defects exclusively. ${ }^{42,43}$ This variation of healing patterns of different types of defects also seemed to be reflected in a large standard deviation of the alveolar bone level changes (Table 3). In spite of these considerations, the selected approach was considered to give the best impression of the EMS effect.

The absence of major clinical effects of EMS on both periodontal soft tissues and alveolar bone do not, however, exclude possible intratissue effects such as altered rates of fibroblast mitosis or collagen production. The complexity of chronically inflamed periodontal tissues that may have caused yet unexplained alterations of bone and tooth substance as well as inhibitory factors for cell growth might have influenced the ability of the cells to respond to the electromagnetic field. Also, previous evidence of an effect of electrical stimulation in extraction wounds ${ }^{33}$ but not in periodontal defects ${ }^{24,25}$ suggest differences in the response to electrical stimulation between cells of experimentally created wounds and naturally occuring periodontal defects.

In spite of the promising findings of laboratory studies, the present clinical study in humans did not confirm the effects of electromagnetic stimulation in periodontal defects during a postsurgical healing period. Within the limits of this study, the magnitude of the alveolar bone level gains and the clinical soft tissue response do not seem to justify the use of electromagnetic stimulation on a regular basis in periodontal therapy.

\section{REFERENCES}

1. Fukuda, E., and Yasuda, I.: On the piezoelectric effect of bone. J Physiol Soc Jpn 12: 1158, 1957.

2. Yasuda, I., Noguchi, K., and Sata, T.: Dynamic callus and electrical callus. J Bone Joint Surg 27A: 1292, 1955.

3. Zengo, A. N., Bassett, C. A. L., Pawluk, R. J., and Prauntgos, G.: In vivo bioelectric potentials in the dentoalveolar complex. Am J Orthod 66: 130, 1974.

4. Cochran, G. V. B., Pawluck, R. J., and Basset, C. A. L.: Stress generated electric potentials in the mandible and teeth. Arch Oral Biol 12: 917, 1967.

5. Fukada, E., Toshiaki, T., and Yasuda, I.: Callus formation by Electret. Jpn J Appl Physiol 14: 2079, 1975.

6. Bassett, C. A. L., Pawluck, R. J., and Becker, R. O.: Effects of electrical currents on bone in vivo. Nature 204: 652, 1964.

7. Friedenberg, Z. B., and Kohanim, M.: The effect of direct current on bone. Surg Gynecol Obstet 127: 97, 1968.

8. Levy, D. D., and Rubin, B.: Inducing bone growth in vivo by pulse stimulation. Clin Orthop 88: 218, 1972.

9. Friedenberg, Z. B., Andrews, E. T., Smolenski, B. I., et al.: Bone reaction to varying amounts of direct current. Surg Gynecol Obstet 11: 894, 1970.

10. Iida, H., Ko, S., Miyashita, Y., et al.: On electric callus produced by alternating current. $J$ Kyoto Prefect Coll Med 60: 561, 1956.

11. Smith, S. D.: Effects of electrode placement on stimulation of adult frog limb regeneration. Ann NY Acad Sci 238: 500, 1974.

12. Becker, R. O.: Stimulation of partial limb regeneration in rats. Nature 235: 109, 1972.

13. Bassett, C. A. L., Pawluck, R. J., and Pilla, A. A.: Acceleration of fracture repair by electromagnetic fields; A surgically non-invasive method. Ann NY Acad Sci 238, 1974.

14. Bassett, C. A. L., Pawluck, R. J., and Pilla, A. A.: Augmentation of bone repair by inductively coupled electromagnetic fields. Science 184: 575, 1974.

15. Bassett, C. A. L., Pilla, A. A., and Pawluk, R. J.: A nonoperative salvage of surgically resistant pseudoarthroses and nonunions by pulsing electromagnetic fields: a preliminary report. Clin Orthop 124: 128, 1977.

16. Brighton, C. T., Friedenberg, Z. B., Mitchell, E. I., and Booth, R. E.: Treatment of non-union with constant direct current. Clin Orthop 124: 106, 1977.

17. Spadaro, J. P.: Electrically stimulated bone growth in animals and man. Clin Orthop 122: 325, 1977.

18. Bassett, C. A. L.: Biophysical principles affecting bone structure. G. H. Bourne (ed), The Biochemistry and Physiology of Bone, pp. 1-76. New York, Academic Press Inc, 1971. 
19. Becker, R. O.: Electrical osteogenesis-pro and con, review. Calcif Tissue Res 26: 93, 1978.

20. Epiker, B. N., and Frost, H. M.: Correlation of bone resorption and formation with the physical behavior of loaded bone. $J$ Dent Res 44: 33, 1965.

21. Norton, L. A.: Implications of bioelectric growth control in orthodontics and dentistry. Angle Orthod 45: 34, 1975.

22. Davidovitch, Z., Shanfeld, J., Iannacone, W., and Korostoff, E.: Enhancement of orthodontic tooth movement in cats by locally applied electric currents (Abstr 190). J Dent Res 56: 588, 1977.

23. Kopczyk, R. A., Norton, L. A., and Kohn, M.: Methods to investigate bioelectric regeneration of bone in periodontal defects. $J$ Dent Res 54: 914, 1975.

24. Jacobs, J. D., and Norton, L. A.: Electrical stimulation of osteogenesis in pathological osseous defects. J Periodontol 47: 311 , 1976.

25. Jacobs, J. D., and Norton, L. A.: Electrical stimulation of osteogenesis in periodontal defects. Clin Orthop 124: 41, 1977.

26. Christel, P., Cerf, G., and Pilla, A. A.: Modulation of rat radial osteotomy repair using electromagnetic current induction. R. Becker (ed), Mechanisms of Growth Control. New York, Charles C. Thomas, Inc, 1981.

27. Vingerling, P. A., van der Kuiz, P., de Groot, K., and Sillevis Smitt, P. A. E.: Non-invasive treatment of alveolar wounds. C. T. Brighton, J. Black, and S. R. Pollack (eds), Electrical Properties of Bone and Cartilage; Experimental and Clinical Applications, pp. 341346. New York, Grune \& Stratton, 1979.

28. Hanks, C. T., Geister, D. E., Kim, J.-S., et al.: DNA synthesis in fetal rat clavarium cells stimulated by microprocessor generated signal. Trans Bioelectrical Repair Growth Soc 1: 3, 1981.

29. Hanks, C. T., Moskwa, J., Kim, J.-S. and Avery, J. K.: In vitro testing for development of coils and waveform for intraoral EM device. Trans Bioelectrical Repair Growth Soc 5: 55, 1985.

30. Hanks, C. T., Kim, J.-S., Makmali, M., et al.: Electromagnetic stimulation of DNA and protein synthesis in vitro. $J$ Dent Res 64: (Special Issue) 280, 1985.

31. Elice, C. E., Chiego, Jr., D. J., and Avery, J. K.: Electromagnetic stimulation of alveolar bone after wounding. $J$ Dent Res 65 : $1377,1986$.

32. Avery, J. K., Chiego, D. J., Ash, M. M., et al.: Device for microdensitometric, adsorptiometric and histopathologic correlative evaluation of wound healing. J Dent Res 58A: 844, 1979.

33. Chiego, D. J., Avery, J. K., Ash, M. M., et al.: Electromagnetic stimulation of new bone in teeth extraction sites. Anat Rec 196: 32A, 1980.

34. Ramfjord, S. P., and Nissle, R. R.: The modified widman flap. $J$ Periodontol 45: 601, 1974.

35. Duckworth, J. E., Judy, P. F., Goodson, J. M., and Socransky, S. S.: A method for the geometric and densitometric standardization of intraoral radiographs. $J$ Periodontol 54: 435, 1983.

36. Schei, O., Holmberg, K., and Nylander, G.: Alveolar bone loss as related to oral hygiene and age. J Periodontol 30: 7, 1959.

37. Knowles, J. W., Burgett, F. G., Nissle, R. R., et al.: Results of periodontal treatment related to pocket depth and attachment level. Eight years. J Periodontol 50: 225, 1979.

38. Ramfjord, S. P., Knowles, J. W., Morrison, E. C., et al.: Results of periodontal therapy related to tooth type. J Periodontol 51: 270, 1980.

39. Lindhe, J., Westfelt, E., Nyman, S., et al.: Long-term effect of surgical/non-surgical treatment of periodontal disease. $J$ Periodontol 11: $448,1984$.

40. Pihlstrom, B. L., McHugh, R. B., Oliphant T. H., and OrtizCampos, C.: Comparison of surgical and nonsurgical treatment of periodontal disease. A review of current studies and additional results after 61/2 years. J Clin Periodontol 10: 524, 1983.

41. Bassett, C. A. L., and Hermann, I.: The effect of electrostatic fields on macromolecular synthesis by fibroblasts in vitro. J Cell Biol 39: 9A, 1968.

42. Rosling, B., Nyman, S., Lindhe, J., and Jern B.: The healing potential of the periodontal tissue following different techniques of periodontal surgery in plaque-free dentitions. A 2-year clinical study. J Clin Periodontol 3: 233, 1976.

43. Rosling, B., Nyman, S., and Lindhe, J.: The effect of systematic plaque control on bone regeneration in infrabony pockets. J Clin Periodontol 3: 38, 1976.

Send reprint requests to: Dr. B. Steffensen, Department of Periodontics, The University of Texas Health Science Center at San Antonio, 7703 Floyd Curl Dr, San Antonio, TX 78284-7894. 